New therapies

\title{
Somatostatin analogue treatment of neuroendocrine tumours
}

\section{Summary}

The long-acting analogues of somatostatin have an established place in the medical treatment of patients with neuroendocrine tumours. They act through binding with specific, high-affinity membrane receptors. Somatostatin analogue therapy is an effective and safe treatment for most growth hormone and thyrothropin-secreting pituitary adenomas. The potential therapeutic consequences of the presence of somatostatin receptors on clinically 'nonfunctioning' pituitary tumours are still uncertain. Somatostatin analogues are not useful in the treatment of patients with prolactinomas, or adrenocorticotropin (ACTH)-secreting adenomas. However, the somatostatin analogue octreotide suppressed pathological ACTH release in some patients with Nelson's syndrome and ACTH and cortisol secretion in several patients with Cushing's syndrome caused by ectopic ACTH secretion. Somatostatin analogues are effective in the sympatomatic treatment of most (metastatic) pancreatic islet cell tumours and most (metastatic) carcinoids. In some of these patients, they also induce tumour stabilisation or reduction. In some patients with (metastatic) medullary thyroid carcinomas, continuous treatment with very high doses of octreotide can be of temporary relief. The clinical effectiveness of somatostatin analogues in patients with small cell lung cancer is currently under investigation. Long-term therapy with somatostatin analogues of catecholamine-secreting (malignant) paragangliomas and phaeochromocytomas has not shown clinical benefits.

Keywords: somatostatin analogues, neuroendocrine tumours

Department of Internal Medicine III, University Hospital, 3015 GD

Rotterdam, The Netherlands

WW de Herder

A-J van der Lely

SWJ Lamberts

Accepted 16 October 1995

\author{
Wouter W de Herder, Aart-Jan van der Lely, Steven WJ Lamberts
}

Somatostatin is a cyclic peptide consisting of 14 amino acids. It is present in various organ systems. This tetradecapeptide exerts an inhibitory regulatory role in the central nervous system, hypothalamus and anterior pituitary gland, the gastrointestinal tract, the exocrine and endocrine pancreas and the immune system. $^{1-3}$

For therapeutic purposes, somatostatin needs to be administered by the intravenous (iv) route due to its short half-life (less than three minutes). The peptide has simultaneous effects in different organ systems, which is usually more a disadvantage than an advantage. Furthermore, post-infusion rebound hypersecretion of hormones occurs. Therefore, analogues of somatostatin without these drawbacks have been synthesized (figure). These analogues are relatively resistant to proteolytic enzymes, which results in longer half-lives.

- Octreotide (SMS 201-995, Sandostatin) is a synthetic octapeptide, which has a half-life of about $113 \mathrm{~min}$. The drug can be administered by multiple subcutaneous (sc) injections, or by continuous sc infusion, and by the iv route, either as a single injection, or as a continuous infusion over many hours or days. A slow-release depot intramuscular (im) formulation of octreotide (Sandostatin-LAR) is expected to be available for clinical use in the near future. This drug has to be administered once every four weeks.

- Somatuline (BIM 23014) is a synthetic, cyclic, octapeptide with a similar therapeutic profile as octreotide. It can be given by the same routes of administration as octreotide. A slow-release im depot formulation (Lanreotide, BIMLA), which needs to be administered every $10-15$ days is currently available.,

- RC 160 (Octastatin, Vapreotide) is a synthetic octapeptide, which is at present undergoing pharmacological testing. ${ }^{6,7}$

Somatostatin (and its analogues) acts through interaction with specific, highaffinity membrane receptors on the responsive cells. ${ }^{6}$ Until now, five different somatostatin receptor subtypes have been identified in normal human tissues, which differ in their binding affinities for somatostatin. ${ }^{8-10}$ After coupling to its membrane receptors, the intracellular effects of somatostatin are mediated via several transduction systems. Most pronounced are its inhibitory effects on adenylate cyclase activity, resulting in a decrease in intracellular cAMP levels. Somatostatin also reduces intracellular calcium levels and induces tyrosine phosphatase activity in a number of tissues..$^{8-10}$ High numbers of somatostatin receptors are expressed on most tumour cells, which originate from cells which
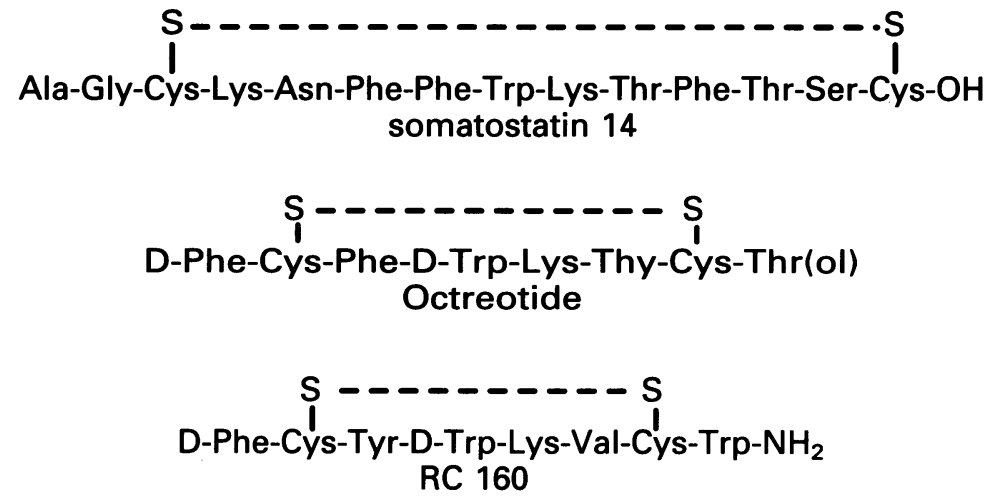

$$
\begin{gathered}
\text { D- } \beta \text { Nal-Cys-Tyr-D-Trp-Lys-Val-Cys-Thr-NH } \\
\text { BIM } 23014
\end{gathered}
$$

Figure Comparative amino acid sequence of somatostatin and its currently available analogues 


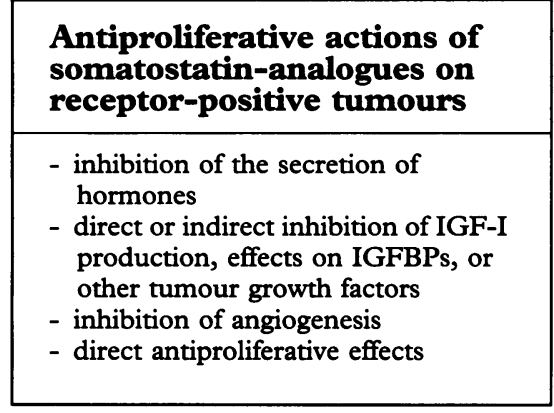

Box 1 also contain these receptors in the physiological state. ${ }^{6}$ This is especially true for growth hormone-secreting pituitary adenomas and gastroenteropancreatic tumours, like islet cell and carcinoid tumours. ${ }^{8,9}$ Somatostatin analogues might also exert an antiproliferative action on receptor-positive tumours, $(a)$ through the inhibition of the secretion of growth hormone and gastroenteropancreatic hormones; $(b)$ through direct or indirect (through growth hormone) inhibition of the production of insulin-like growth factor I (IGF-I), the IGF-binding proteins (IGFBPs), or other tumour growth factors; $(c)$ through the inhibition of angiogenesis; and/or $(d)$ thirough direct antiproliferative effects on the tumour by binding to specific somatostatin receptors. ${ }^{9}$

This review describès the role of somatostatin and its long-acting analogues in the management of neuroendocrine tumours.

\section{Pituitary tumours}

\section{ACROMEGALY}

Acromegaly is almost exclusively caused by a growth-hormone-secreting pituitary tumour. The most important clinical features include characteristic disfigurements of the face, hands and feet (the acra), headaches, excessive perspiration, paraesthesias in fingers and toes, and fatigue. ${ }^{11-13}$ Untreated, the disorder has an approximately two-fold increased mortality rate due to cardiovascular diseases, diabetes mellitus and an increased incidence of malignancies. ${ }^{11,13}$ Therefore, effective and safe long-term medical treatment could be of benefit in young acromegalics after noncurative surgery, or for a limited period in expectation of the clinical success of stereotactic radiosurgery or external pituitary radiotherapy. ${ }^{11,13}$ Somatotroph pituitary tumours of elderly patients in general show a high sensitivity to the growth hormone and IGF-I suppressive effect of octreotide, which suggests that somatostatin analogue therapy may be used as primary treatment in these patients. ${ }^{12,13}$ Long-term therapy of acromegalic patients with octreotide $(100 \mu \mathrm{g} \mathrm{sc}$, two or three times per day) caused a reduction of excessive perspiration, headaches, paraesthesias, fatigue and soft tissue swelling. ${ }^{8,11,13} \mathrm{~A}$ normalisation of initially elevated circulating IGF-I levels could be demonstrated in $68 \%$ of patients, while mean 24-h levels of growth hormone decreased by more than $80 \% .^{8,11,13}$ Long-term somatostatin analogue therapy may result in a normalisation of growthhormone-dependent IGF-binding protein-3 (IGFBP-3) levels, which is the major storage form of IGFs in the circulation. ${ }^{14}$ Somatostatin analogues also cause a significant increase in circulating IGFBP-1 levels. This $28-\mathrm{kD}$ protein is generally found to be an inhibitor of IGF-I actions. ${ }^{15}$ A slight, but significant decrease in pituitary tumour size was observed during octreotide treatment in about $50 \%$ of patients. The mechanism of tumour shrinkage is probably due to a reduced growth hormone content. ${ }^{8,11,13}$ Somatotroph tumours retain their sensitivity to octreotide, at least for more than a decade. Escape from therapy of initially somatostatin-analogue-sensitive tumours has not yet been reported. $8,11,13$

Preliminary studies indicate that the im slow-release depot preparations, Sandostatin-LAR (30 mg injected once a month) and Lanreotide (30 mg injected im once every 10-15 days), are well-tolerated in acromegaly and do control growth hormone and IGF-I levels. ${ }^{4,5}$ Although the pharmacokinetic properties of the three octapeptide somatostatin analogues have not yet been compared in acromegaly, in vitro data point to comparable biological activities in vivo (Hofland, LJ, personal communication).

\section{THYROTROPIN-SECRETING ADENOMAS}

Hyperthyroidism secondary to thyroid-stimulating hormone (thyrotropin, TSH) hypersecretion is very uncommon. It is caused by a thyrotroph pituitary tumour, or is due to insensitivity of the pituitary thyrotroph cells to thyroid hormones. Several studies have shown that short-term (3-4 months) octreotide treatment (50-100 $\mu \mathrm{g} \mathrm{sc}$, two or three times daily) of patients with TSHsecreting macro-adenomas (tumour diameter $>1 \mathrm{~cm}$ ) resulted in a decrease of elevated serum TSH and glycoprotein hormone alpha-subunit levels in virtually all patients, and a normalisation of thyroid hormone levels in about $73 \%$ of patients. Partial tumour shrinkage was observed in $40 \%$ of patients receiving long-term therapy. ${ }^{16}$ Somatostatin analogues should therefore be considered an effective treatment for these tumours after noncurative surgery and/or radiotherapy.

\section{PROLACTINOMAS}

Normal prolactin secretion and pathological secretion by micro- (tumour diameter $<1 \mathrm{~cm}$ ) and macro-adenomas are not sensitive to the currently 
available somatostatin analogues. Interestingly, however, pathological prolactin secretion by mixed growth hormone/prolactin secreting tumours, representing about $15 \%$ of the tumours found in acromegalic patients, is often suppressed by octreotide, in parallel with tumour growth hormone release. ${ }^{8}$

\section{ADRENOCORTICOTROPIN-SECRETING ADENOMAS}

Adrenocorticotropin (ACTH)-secreting microadenomas do not express somatostatin(-analogue) receptors. In patients with Cushing's disease, suppression of ACTH and/or cortisol levels by octreotide has not been observed. Octreotide suppressed ACTH release in three of four patients with Nelson's syndrome. Chronic octreotide therapy has been shown to suppress ACTH and cortisol secretion in several patients with Cushing's syndrome caused by ectopic ACTH secretion from (metastatic) gastroenteropancreatic tumours, small cell lung cancers, carcinoids and medullary thyroid carcinomas. ${ }^{7-9,17-19}$

\section{HORMONALLY INACTIVE AND GONADOTROPIN-SECRETING ADENOMAS}

Clinically nonfunctioning pituitary adenomas and/or gonadotropinomas in general do not present with signs and symptoms associated with hormonal overproduction. Most tumours are recognised when clinical symptoms due to a large tumour volume develop, such as visual field defects (due to chiasmal compression) and hydrocephalus. Therefore, most of these tumours are large macro-adenomas at presentation. Low-dose (150-300 $\mu \mathrm{g} \mathrm{sc}$ per day), or highdose (1200 $\mu \mathrm{g}$ by continuous sc infusion) octreotide therapy of patients with clinically nonfunctioning pituitary macro-adenomas did not result in significant tumour shrinkage. Significant improvement of visual field defects was observed in three of four patients in the high dose group and in one of nine patients in the low-dose group. ${ }^{20,21}$ However, shortly after the start of octreotide therapy in patients with diseases in the pituitary region and presenting with visual defects, improvement of visual-evoked potentials has been observed, which may be related to a direct effect of the octreotide in the optical system. ${ }^{8}$ In conclusion, the potential therapeutic consequences of somatostatin receptors on clinically nonfunctioning pituitary tumours are uncertain.

\section{Gastroenteropancreatic tumours}

Gastroenteropancreatic tumours are in general slow-growing. These tumours originate from the islet cells of the pancreas, but they may also occur in the stomach, duodenum or small intestinal tract. Islet cell tumours have been traditionally named according to the hormone(s) they secrete, like gastrinomas, glucagonomas, VIP(vaso-intestinal peptide)-omas, insulinomas and somatostatinomas. ${ }^{22,23}$ Together with other neuroendocrine tumours, they have been classified as APUDomas (Amine Precursor Uptake and Decarboxylation). ${ }^{24}$ With the exception of small insulinomas, most are malignant and have already metastasised at the time of diagnosis. The largest part of these tumours express somatostatin(-analogue) receptors. ${ }^{6}$ Most of the clinical symptomatology in these patients is caused by the pathological secretion of hormones. Attempts at surgical debulking, embolisation of the tumour's blood supply and chemotherapy were the only available therapies until the clinical introduction of somatostatin analogues. ${ }^{22}$ The clinical symptomatology like diarrhoea, dehydration, hypokalaemia, peptic ulceration, life-threatening hypoglycaemia and necrolytic skin lesions were well controlled by chronic administration of $100 \mu \mathrm{g}$ octreotide sc by two or three daily injections, in most patients with VIP-omas, gastrinomas, insulinomas, and glucagonomas (table). ${ }^{9,22,23}$ Objective tumour regression was demonstrated in less than $20 \%$ of patients and stabilisation of

Table Established clinical uses of somatostatin analogues in APUD-omas

\begin{tabular}{|c|c|c|}
\hline Tumour & Clinical syndrome & Pharmacological actions of somatostatin analogues \\
\hline $\begin{array}{l}\text { GH-oma } \\
\text { TSH-oma } \\
\text { Gastrinoma } \\
\text { VIPoma } \\
\text { Carcinoid tumour } \\
\text { Insulinoma } \\
\text { Glucagonoma }\end{array}$ & $\begin{array}{l}\text { acromegaly } \\
\text { central hyperthyroidism } \\
\text { Zollinger-Ellison syndrome } \\
\text { Verner-Morrison syndrome } \\
\text { carcinoid syndrome } \\
\text { hypoglycaemic attacks } \\
\text { necrolytic erythema, diabetes mellitus }\end{array}$ & $\begin{array}{l}\text { GH } \downarrow, \text { IGF-I } \downarrow \text {, IGFBP-3 } 3 \text {, IGFBP- } 1 \uparrow \text {, tumour volume } \downarrow \text {, symptoms }{ }^{\star} \downarrow \\
\text { TSH } \downarrow, T_{4} \downarrow, F_{4} \downarrow, \alpha \text {-subunits } \downarrow \text {, tumour volume } \downarrow \text {, hyperthyroidism } \downarrow \\
\text { gastrin } \downarrow \text {, gastric HCl secretion } \downarrow \text {, peptic ulceration } \downarrow \text {, diarrhoea } \downarrow \\
\text { VIP } \downarrow \text {, diarrhoea } \downarrow, K^{+} \uparrow \text {, dehydration } \downarrow \\
\text { flushing attacks } \downarrow \text {, diarrhoea } \downarrow \text {, reverses carcinoid crisis, tumour control, } \\
\text { urinary 5-HIAA } \downarrow \\
\text { insulin } \downarrow \text {, hypoglycaemic symptoms } \downarrow \\
\text { glucagon } \downarrow \text {, necrolytic erythema } \downarrow \text {, diabetes mellitus } \downarrow\end{array}$ \\
\hline
\end{tabular}

${ }^{\star}=$ see text for details; GH, growth hormone; IGF, insulin-like growth factor; IGFBP, IGF-binding protein; TSH, thyrotropin; $\mathrm{T}_{4}$, thyroxine; FT4, free thyroxine; VIP, vaso-intestinal peptide; 5-HIAA, 5-hydroxyindole acetic acid 
tumour progression occurred in the majority of patients. Radiographic evidence of increased intratumoural necrosis was found.,22,23 However, insensitivity to octreotide develops within months in almost all patients. ${ }^{25}$ This is probably due to a therapy-induced preferential selection of somatostatin-receptor-negative tumour cell clones; somatostatin receptor desensitization, or downregulation do not seem to play a major role. ${ }^{25}$

In conclusion, octreotide has a place in the symptomatic treatment of islet cell tumours, both before and after surgical debulking, in combination with or before embolisation and before chemotherapy and/or in combination with alpha-interferon administration.

Carcinoid tumours are malignant tumours originating from enterochromaffin cells, which are dispersed throughout the body, but occur primarily in the submucosa of the intestinal tract, main bronchi and in the pancreas. ${ }^{9,22}$ The primary tumours and the spread of disease are often difficult to localize with current radiological techniques. Small carcinoids that have not yet metastasised rarely cause symptoms, but they can lead to mesenteric fibrosis, resulting in twisting of the bowel, intestinal obstruction and discontinuation of intestinal of blood supply, resulting in intestinal infarction. ${ }^{22}$ Most carcinoids are eventually diagnosed when the carcinoid syndrome has developed. This syndrome occurs when increased amounts of humoral products are present in the systemic circulation. ${ }^{22,26,27}$ The symptomatology of the carcinoid syndrome consists of cutaneous flushing and diarrhoea in $75 \%$ of cases. Fibrosis of the right-sided endocardium, leading to tricuspid and pulmonic valvular disease, bronchoconstriction and pellagra occur in less than half of the patients. ${ }^{22,27}$ Carcinoid tumours arising in the small bowel frequently metastasise, accounting for more than $75 \%$ of cases of carcinoid syndrome. ${ }^{27}$ In these patients, a life-threatening carcinoid crisis with intense cutaneous flushing, severe diarrhoea, abdominal cramps, tachycardia, hypertension or profound hypotension may occur. ${ }^{22,27}$ Patient survival in general depends on the severity of the symptoms and complications caused by the excessive production of humoral factors, the site of the primary tumour and the extent of metastatic spread. With local disease, the 5 -year survival is $94 \%$, decreasing to $65 \%$ in patients with regional lymph node involvement. The 5-year survival for patients with distant metastases is less than $20 \%$. Primary tumours $<1 \mathrm{~cm}$ have seldom metastazised, while generally about $90 \%$ of primary tumours $>2 \mathrm{~cm}$ have metastases. Some patients have metastatic disease without serious symptoms. ${ }^{26,27}$ As in patients with gastroenteropancreatic tumours, somatostatin analogue treatment results in a significant improvement of symptomatology in patients with the carcinoid syndrome. ${ }^{22,26,27}$ Treatment with $100 \mu \mathrm{g}$ octreotide sc, two or three times daily resulted in a complete disappearance of flushing episodes in about $60 \%$ of patients, while in $87 \%$ the frequency and/or severity of the flushing periods were reduced to less than $50 \%$. Diarrhoea disappeared in $32 \%$, while more than $50 \%$ improvement has been reported in $77 \%$ of patients. The increased urinary excretion of the serotonin metabolite, 5-hydroxyindole acetic acid, a biochemical marker of the carcinoid syndrome, was significantly reduced in more than half the patients during octreotide treatment. ${ }^{9,22,26,27}$ Somatostatin analogue treatment results in objective tumour regression in about $20 \%$ of patients, while median progression-free survival is increased from 3.5 to 15 months by octreotide. ${ }^{9,22,26,27}$ A carcinoid crisis can be effectively treated by an acute iv bolus injection of $50-500 \mu \mathrm{g}$ octreotide. ${ }^{26,27}$ The efficacy of combination therapy of octreotide with alpha-interferon, potentially causing synergistic effects, is currently under investigation. However, as was also concluded for gastroenteropancreatic tumours, therapy with octreotide and/or interferons is predominantly palliative. Total surgical removal is the primary therapy of choice, while debulking can significantly reduce symptoms in patients with metastatic carcinoids.

\section{Other neuroendocrine tumours}

As described by Pearse, pituitary adenomas and gastroenteropancreatic tumours are positive for the neuroendocrine markers predicted in the APUD cell concept (box 2). ${ }^{24}$ It was therefore logical to investigate other tumours of this class, like paraganglioma, medullary thyroid carcinoma, phaeochromocytoma and small cell lung cancer, for the presence of somatostatin receptors and to evaluate the clinical response to somatostatin analogues in patients with these tumours.

\section{PHAEOCHROMOCYTOMA/PARAGANGLIOMA}

At present, long-term therapy of catecholamine-secreting (malignant) paragangliomas and phaeochromocytomas with somatostatin analogues has not 
Tumours of the APUD cell system

Site of origin:

Anterior pituitary gland:

Adrenal medulla:

Extra-adrenal paraganglia:

Thyroid C cells:

Pancreatic islets:

GI tract endocrine cells:

Bronchopulmonary tree endocrine cells: Merkel cells, skin:
Tumour type

corticotroph, thyreotroph, somatotroph, lactotroph and gonadotroph adenoma/clinically nonfunctioning tumour

phaeochromocytoma

paraganglioma

medullary thyroid carcinoma

insulinoma, somatostatinoma, glucagonoma, VIPoma, carcinoid, pancreatic polypeptideoma, gastrinoma, undifferentiated tumour

carcinoid, gastrinoma, undifferentiated tumour

small cell lung cancer, carcinoid

trabecular carcinoma

Box 2

shown clinical benefits. In vitro, a high density of somatostatin receptors has been demonstrated in almost all paragangliomas and the majority of phaeochromocytomas. ${ }^{6,9}$

\section{MEDULLARY THYROID CARCINOMA}

Medullary thyroid carcinoma arise from the parafollicular calcitonin-secreting $\mathrm{C}$ cells of the thyroid. A number of different regulatory peptides are produced by this type of tumour, including somatostatin. Contradictory results with regard to the therapeutic effects of somatostatin analogues in these patients have been obtained. Initial studies showed no effects of therapy with relatively low doses of octreotide ( $<300 \mu \mathrm{g}$ per day, by sc bolus injections, or continuous sc or iv infusion) on symptoms, biochemical parameters (like serum calcitonin and/or levels of carcinoembryonic antigen). ${ }^{28,29}$ Treatment with relatively high doses of octreotide (up to $1500 \mu \mathrm{g}$ daily by continuous sc infusion) was reported to result in a temporary (3-17 months) improvement of symptoms and biochemical parameters, but no significant tumour reduction. ${ }^{28,29}$ In contrast, more recent studies show that high dose octreotide therapy in medullary thyroid carcinoma ( $<1000 \mu \mathrm{g}$ per day) did not result in clinical benefits. ${ }^{30,31}$ In conclusion, these findings suggest that only continuous treatment with very high doses of octreotide can be of temporary relief in some patients with medullary thyroid carcinoma.

SMALL CELL LUNG CANCER

Small cell lung cancer has been hypothesised to originate from the so-called Kulchitsky cells which are normal cells with neuroendocrine characteristics found in the tracheobronchial mucosa. The clinical effectiveness of somatostatin analogues in these patients is currently under investigation. ${ }^{9}$

\section{Adverse effects of somatostatin analogues}

Apart from nausea, transient abdominal cramps, flatulence, loose (fatty) stools, and/or diarrhoea, and local reactions at the site of injection, no important side-effects have been observed during octreotide treatment. ${ }^{9,11,13}$ These sideeffects show a tendency to resolve in the course of therapy. In $20-30 \%$ of patients gallstones are formed de novo, but these remain virtually always asymptomatic. ${ }^{9,11,13}$ Octreotide also causes a short-term inhibition and/or delay of insulin release in response to meals, but this is only accompanied by a slight decrease in glucose tolerance in some patients, without notable changes in $\mathrm{HbA}_{1 \mathrm{C}}$ levels. ${ }^{8,9,11,13}$

\section{The value of in vivo somatostatin-receptor imaging}

Virtually all APUDomas express a high density of somatostatin receptors. ${ }^{6,7,9,32}$ Previous studies have shown that the in vitro detection of somatostatin receptors on APUDomas by autoradiography is closely correlated with the positive scintigrams obtained in vivo using gamma camera pictures obtained after injection of ${ }^{123} \mathrm{I}-\mathrm{Tyr}^{3}$-octreotide, or ${ }^{111} \mathrm{In}$-pentetreotide (OctreoScan, Mallinckrodt, Petten, The Netherlands). ${ }^{6,7,9,32}$ The pre-operative in vivo hormonal studies obtained after the administration of somatostatin(-analogues), the in vitro studies with cultured tumour cells after the administration of somatostatin(-analogues) and the results of in vivo somatostatin receptor scintigraphy are closely correlated. $6,7,9,32$ This suggests that a positive scintigram in a patient with an APUDoma predicts a therapeutic effect of somatostatin analogues on 
1 Reichlin S. Somatostatin (first of two parts). $N$ Engl F Med 1983; 309: 1495-501.

2 Reichlin S. Somatostatin (second of two parts). $N$ Engl f Med 1983; 309: 1556-63.

3 Reichlin S. Neuroendocrine-immune interactions. N Engl f Med 1993; 329: 1246-53.

4 Morange I, De Boisvilliers F, Chanson P, et al. Slow release lanreotide treatment in acromegalic patients previously normalized by octreotide. $\mathscr{f}$ Clin Endocrinol Metab 1994; 79: 145-51.

5 Caron P, Cogne M, Gusthiot-Joudet B, Wakim $S$, Catus F, Bayard F. Intramuscular injections S, Catus F, Bayard F. Intramuscular injections
of slow-release lanreotide (BIM 23014) in of slow-release lanreotide (BIM 23014) in acromegalic patients previously treated with (SMS 201-995). Eur $\mathcal{f}$ Endocrinol 1995; 132: (SMS 201

6 Reubi JC, Laissue J, Krenning E, Lamberts SW. Somatostatin receptors in human cancer: incidence, characteristics, functional correlates and clinical implications. $\mathcal{F}$ Steroid Biochem Mol Biol 1992; 43: 27-35.

7 Lamberts SW, Hofland LJ, de Herder WW, Kwekkeboom DJ, Reubi JC, Krenning EP. Octreotide and related somatostatin analogs in the diagnosis and treatment of pituitary disease and somatostatin receptor scintigraphy. Front Neuroendocrinol 1993; 14: 27-55.

8 Lamberts SW. The role of somatostatin in the regulation of anterior pituitary hormone secreregulation of anterior pituitary hormone secre-
tion and the use of its analogs in the treatment of tion and the use of its analogs in the treatment of
human pituitary tumors. Endocr Rev 1988; 9: human

9 Lamberts SW, Krenning EP, Reubi JC. The role of somatostatin and its analogs in the diagnosis and treatment of tumors. Endocr Rev 1991; 12: 450-82.

10 Lamberts SW, Krenning EP, Reubi JC. Somatostatin. Role in tumour treatment and diagnosis. Endocr Rev Monogr 1993; 1: 245-6.

11 Ezzat S, Snyder PJ, Young WF, et al. Octreotide treatment of acromegaly A randomized, multi-

12 van der Lely AJ, Harris AG, Lamberts SW. The sensitivity of growth hormone secretion to medical treatment in acromegalic patients: influence of age and sex. Clin Endocrinol 1992; 37: 181-5. hormonal hypersecretion by these tumours. ${ }^{7,18,19,32}$ Somatostatin receptor scintigraphy, however, is not specific for APUDomas, as somatostatin receptors have also been recognised in vitro and demonstrated in vivo on a variety of other tumours, including meningiomas, well-differentiated brain tumours and lymphomas, but also in granulomas and other lesions, such as those seen in autoimmune disease with systemic involvement. ${ }^{32}$ This makes somatostatin receptor scintigraphy a useful tool in the diagnostic work-up of patients with APUDomas, to localise the primary tumour, as well as the metastatic spread. However, in vivo scintigraphy is not suitable for the differential diagnosis of these tumours. ${ }^{32}$

13 Anonymous. Consensus statement: benefits versus risks of medical therapy for acromegaly A cromegaly Therapy Consensus Development Panel. Am f Med 1994; 97: 468-73.

14 Jorgensen JO, Moller N, Moller J, Weeke J Blum WF. Insulin-like growth factors (IGF)and -II and IGF binding protein-1, -2 , and -3 in patients with acromegaly before and after adenomectomy. Metabolism 1994; 43: 579-83.

15 de Herder WW, Uitterlinden P, van der Lely AJ, Hofland LJ, Lamberts SWJ. Octreotide, but not bromocriptine, increases circulating insulin-like bromocriptine, increases circulating insulin-like growth factor binding protein 1 levels in

16 Chanson P, Weintraub BD, Harris AG. OctreoChanson P, Weintraub BD, Harris AG. Octreo-
tide therapy for thyroid-stimulating hormonesecreting pituitary adenomas A follow-up of 52 patients. Ann Intern Med 1993; 119: 236-40.

17 de Herder WW, Krenning EP, Malchoff CD, al. Somatostatin receptor scintigraphy: its value in tumor localization in patients with Cushing's syndrome caused by ectopic corticotropin corticotropin-releasing hormone secretion. $A m \mathcal{F}$ Med 1994; 96: 305-12.

18 Lamberts SW, de Herder WW, Krenning EP, Reubi JC. A role of (labeled) somatostatin analogs in the differential diagnosis and treatment of Cushing's syndrome. $¥$ Clin Endocrinol Metab 1994; 78: 17-9.

19 Lamberts SW, de Herder WW, Kwekkeboom DJ, vd Lely AJ, Nobels FR, Krenning EP. Current tools in the diagnosis of pituitar tumours. Acta Endocrinol Copenh 1993; 129 suppl 1: 6-12.

20 de Bruin TW, Kwekkeboom DJ, van't Verlaa $\mathrm{JW}$, et al. Clinically nonfunctioning pituitary adenoma and octreotide response to long term high dose treatment, and studies in vitro. $\mathcal{F} \mathrm{Clin}$ Endocrinol Metab 1992; 75: 1310-7.

21 Merola B, Colao A, Ferone D, et al. Effects of a chronic treatment with octreotide in patients with functionless pituitary adenomas. Horm Res 1993; 40: 149-55.

22 Moertel CG. An odyssey in the land of small tumors. $f$ Clin Oncol 1987; 5: 1502-22.
23 Wynick D, Bloom SR. The use of the longacting somatostatin analog octreotide in the treatment of gut neuroendocrine tumors. $\mathcal{F}$ Clin Endocrinol Metab 1991; 73: 1-3.

24 Pearse AG, Takor TT. Neuroendocrine embryology and the APUD concept. Clin Endocrinol

25 Wynick D, Anderson JV, Williams SJ, Bloom ڤै SR. Resistance of metastatic pancreatic endo- $\overrightarrow{0}$ crine tumours after long-term treatment with the somatostatin analogue octreotide (SMS 201995). Clin Endocrinol 1989; 30: 385-8.

$26 \mathrm{Kvols}$ LK. Therapeutic considerations for the $\mathcal{O}$ malignant carcinoid syndrome. Acta Oncol 1989; 28: 433-8. tumors and the malignant carcinoid syndrome. N

28 Modigliani E, Chayvialle JA, Cohen R, et al. $\infty$ in perfusion on basal and pentagastrin-stimu- is lated calcitonin levels in medullary thyroid carcinoma. Horm Metab Res 1988; 20: 773-5.

29 Mahler C, Verhelst J, de Longueville M, Harris 음 A. Long-term treatment of metastatic medullary thyroid carcinoma with the somatostatin analogue octreotide. Clin Endocrinol 1990; 33: 261-9. Rodigliani E, Cohen R, Joannidis $\mathrm{S}, e t$ al. Results of long-term continuous subcutaneous

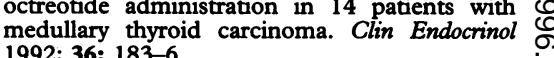

31 Frank-Raue K, Ziegler R, Raue F. The use of octreotide in the treatment of medullary thyroid carcinoma. Horm Metab Res 1993; 27 (suppl): 44-7.

32 Krenning EP, Kwekkeboom DJ, Bakker WH, e al. Somatostatin receptor scintigraphy with [111In-DTPA-D-Phe1]- and [123I-Tyr3]-octreotide: the Rotterdam experience with more than 1000 patients. Eur $\mathcal{F}$ Nucl Med 1993; 20: 716-31.
27 Kvols LK, Reubi JC. Metastatic carcinoid Effect of a somatostatin analog (SMS 201-995) है 